\title{
Are Plant Species' Richness and Diversity Influenced by Fragmentation at a Microscale?
}

\author{
Jesús Aguirre-Gutiérrez ${ }^{1,2}$ \\ ${ }^{1}$ Naturalis Biodiversity Center, Darwinweg 2, 2300 RA Leiden, The Netherlands \\ ${ }^{2}$ Institute for Biodiversity and Ecosystem Dynamics (IBED), University of Amsterdam, Science Park 904, 1098 HX, \\ Amsterdam, The Netherlands
}

Correspondence should be addressed to Jesús Aguirre-Gutiérrez; j.aguirregutierrez@uva.nl

Received 3 October 2013; Accepted 4 November 2013; Published 16 January 2014

Academic Editor: Alexandre Sebbenn

\begin{abstract}
Copyright (C) 2014 Jesús Aguirre-Gutiérrez. This is an open access article distributed under the Creative Commons Attribution License, which permits unrestricted use, distribution, and reproduction in any medium, provided the original work is properly cited.

It is argued that forest fragmentation has negative effects on biodiversity at the short and long term; however, these effects might be dependent on the specific vegetation of the study area and its intrinsic characteristics. The processes leading to fragmentation are very diverse and many of them have anthropogenic causes as logging actions and clearings for agricultural fields. Furthermore, it is thought that scale plays an important role in the expected effects of fragmentation on biodiversity. In this study the effect of forest fragmentation and its impact on the woody plants species, richness and diversity are analysed considering three vegetation types in a poorly studied and difficult access biodiversity hotspot in northern Mexico. The results show that the effects of fragmentation are dependent on the vegetation type and that these are not strongly related to the species richness, and diversity in a microscale $\left(100 \mathrm{~m}^{2}\right)$. Fragmentation effects on biodiversity must be analysed in a broad scale, considering the fragment as a whole. Furthermore, conservation priority should be given to the larger fragments, which could potentially maintain a higher portion of biodiversity. Management should also be focused on increasing the connectivity between these big and medium size forest patches.
\end{abstract}

\section{Introduction}

The processes generating forest loss and habitat fragmentation are recognized as a principal cause of biodiversity decline and are the greatest ecological problem in tropical developing countries [1-6]. These processes increase the vulnerability of the species that inhabit the forest ecosystem by reducing the suitable habitat and by generating patch isolation $[7,8]$. Thus, habitat loss and fragmentation are usually perceived as having negative effects on biodiversity (i.e., $[9,10]$ ) due to the reduction in area available, which decreases the species' effective population sizes, and to the increase in the number of smaller forest fragments, which also modify the microenvironmental characteristics of the landscape. However, there are studies that claim that forest fragmentation can have positive $[11,12]$ or even inconsistent effects [13], depending on the species analysed and the landscape size and structure.

It is argued that larger fragments might contain more species than small fragments and that when the patch's area decreases, it has higher implications for core area species than for the edge ones. However, also contradictory results have been obtained (i.e., [14-16]) reflecting the need of more information resulting from field-based studies carried out in different habitats, as these are mostly carried out in tropical ecosystems (i.e., $[17,18]$ ), and with different levels of fragmentation.

It has also been proposed that the number of individuals per species in a given "forest patch" is conditioned not only by the area available but also by the dispersal capacity of each species [19], mainly because the fragmentation processes generate scattered and isolated patches, reducing in this way the capacity of the organisms to disperse [20]. Furthermore, the patch's species' richness may also be defined by the environmental conditions, the species' life histories, and the ecological conditions of the fragments, which can determine the quality of the resources available $[16,21,22]$.

The scale at which the study is carried out is one of the most important factors when analysing species, richness and 
diversity changes as the variables impacting the species in a given area at a given scale might not be as important when analysed at a different scale [12, 23-25].

This study analyses the impact that forest fragmentation, as a function of the forest patch characteristics, has on the woody plants species, richness and diversity of a poorly studied mountainous ecosystem in northern Mexico. The fragmentation impacts on biodiversity are studied in the complete landscape as an entity. Then, this is further divided by vegetation types (coniferous, nonconiferous, and scattered vegetation) as a surrogate for spatial scale in order to investigate how fragmentation affects the different vegetation types separately.

\section{Study Area}

The study area is located in a poorly studied mixed coniferous-nonconiferous forest ecosystem in the Sierra Madre Occidental, in the northern state of Chihuahua, Mexico (Figure 1). It comprises an area of $100 \mathrm{~km}^{2}$ located within the $107^{\circ} 24^{\prime} 48^{\prime \prime} \mathrm{W}-107^{\circ} 18^{\prime} 43^{\prime \prime} \mathrm{W}$ and $27^{\circ} 57^{\prime} 21^{\prime \prime} \mathrm{N}-27^{\circ} 51^{\prime} 56^{\prime \prime} \mathrm{N}$. The main land cover is pine forest and mixed pine-oak forest. The altitude ranges between approximately $2300 \mathrm{~m}$ and $2800 \mathrm{~m}$ above sea level. Deep canyons characterize the morphology of the region with abrupt changes in elevation and slope, which results in a strong climatic gradient. The mean annual precipitation varies between $200 \mathrm{~mm}$ and $2500 \mathrm{~mm}$ and the mean annual temperature ranges from $-3^{\circ} \mathrm{C}$ to more than $22^{\circ} \mathrm{C}$. The area is located within an international biodiversity hot spot [26] and within one of the Priority Terrestrial Regions for conservation in Mexico (RTP 30, Región Terrestre Prioritaria [27]).

\section{Methods}

3.1. Image Data Collection and Preprocessing. One cloud free Landsat ETM+ datasets was downloaded from the Global Land Cover Facility database (http://www.landcover.org/), from October 17, 2006 (WGS 84, UTM zone 13N, path 033, row 041), with a pixel size of $30 \times 30 \mathrm{~m}$ for all the spectral bands used. The image was orthorectified using a $30 \mathrm{~m}$ resolution digital elevation model [28] in ArcInfo 10 [29].

3.2. Image Classification. The Landsat image was classified using a combined pixel-based and object-based method for satellite image classification [30]. An accuracy assessment was carried out with 100 ground truth points in the field, resulting in a 95\% overall classification accuracy. Seven Land Use/land Cover (LULC) classes were derived from the classification process: (a) coniferous forest, (b) scattered vegetation, (c) non coniferous forest, (d) water, (e) bare soil, (f) agriculture and (g) urban, (Figure 2; Table 1). For further details about the classification process see Aguirre-Gutiérrez et al. [30].

3.3. Fragment Selection and Sampled Vegetation Classes. The forest patches of the complete study area were classified
TABLE 1: Description of the Land Use/Land Cover classes used during the classification analysis.

\begin{tabular}{|c|c|}
\hline Land cover class & Description \\
\hline (1) Coniferous forest & $\begin{array}{l}\text { Forest patches dominated by coniferous } \\
\text { plant species, mostly Pinus spp. }\end{array}$ \\
\hline (2) Scattered vegetation & $\begin{array}{l}\text { Mixed vegetation with a scattered } \\
\text { distribution—shrubs and small trees }\end{array}$ \\
\hline (3) Water & $\begin{array}{l}\text { Water bodies such as lakes and } \\
\text { reservoirs }\end{array}$ \\
\hline (4) Nonconiferous forest & $\begin{array}{l}\text { Forest patches dominated by } \\
\text { nonconiferous plant species, as Quercus } \\
\text { spp. }\end{array}$ \\
\hline (5) Bare soil & $\begin{array}{l}\text { Areas without vegetation, not water and } \\
\text { not urban }\end{array}$ \\
\hline (6) Agriculture & Crop fields, pastures \\
\hline (7) Urban & $\begin{array}{l}\text { Built-up land for residential or } \\
\text { commercial purposes }\end{array}$ \\
\hline
\end{tabular}

by size as small, medium, and large. For the patch size classification threshold, the 33rd and 66th percentile of the polygons area values were used. The small patches had sizes up to $0.005 \mathrm{~km}^{2}$, medium patches had sizes above $0.005 \mathrm{~km}^{2}$ but equal to or below $0.014 \mathrm{~km}^{2}$, and large fragments were those with areas above $0.014 \mathrm{~km}^{2}$. The three forest classes obtained from the image classification process coniferous, nonconiferous and scattered vegetation, were used as the sampling sites and are used for the subsequent analysis.

The species sampling was carried out in 100 forest fragments chosen by a stratified random sampling procedure using Hawth's analysis tools [32] in ArcInfo v.10 [29]. For each forest class, 11 patches per size (33 by forest class) were selected, with the exception of the small "Scattered vegetation" class from which 12 polygons were sampled. No more patches were selected because of accessibility problems in the area, mainly due to the presence of drug cartels (see [33]).

3.4. Field Data Collection. Each selected forest fragment was surveyed using one plot of $10 \times 10$ meters, as suggested by Zuñiga [34] for tree and shrub sampling in forest ecosystems. Plant collection was carried out between January and March 2010. The plots were located at least 10 meters inside the assessed polygons in order to avoid possible edge effects. All woody plants equal to or taller than $30 \mathrm{~cm}$ were collected, counted, and identified at the IBUG herbarium at the University of Guadalajara, where voucher specimens were deposited. All the woody plants collected were classified by their principal seed dispersal mechanism using flora databases and published data (i.e, [35-37]). Position and elevation data were obtained in the field with a GPS device [38]; slope information was derived from a Digital Elevation Model (DEM [28]) with a resolution of $30 \times 30$ meters.

3.5. Fragment Characteristics. The fragment variables used during the analysis to describe the fragments characteristics or fragmentation status of the forest class (Table 2) 


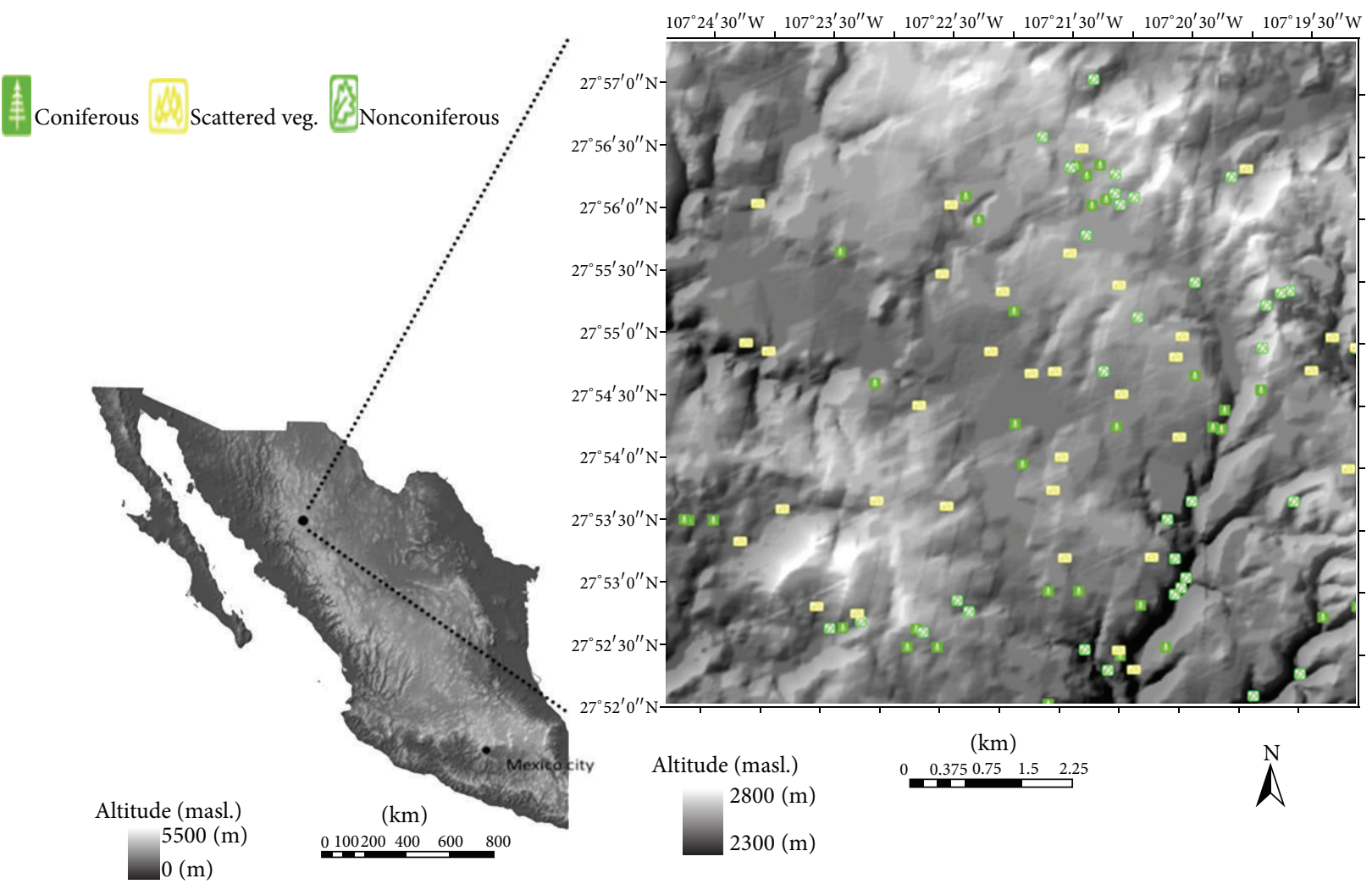

FIgure 1: Study area location within the Sierra Tarahumara in the Sierra Madre Occidental, Chihuahua Mexico, and sampling sites.
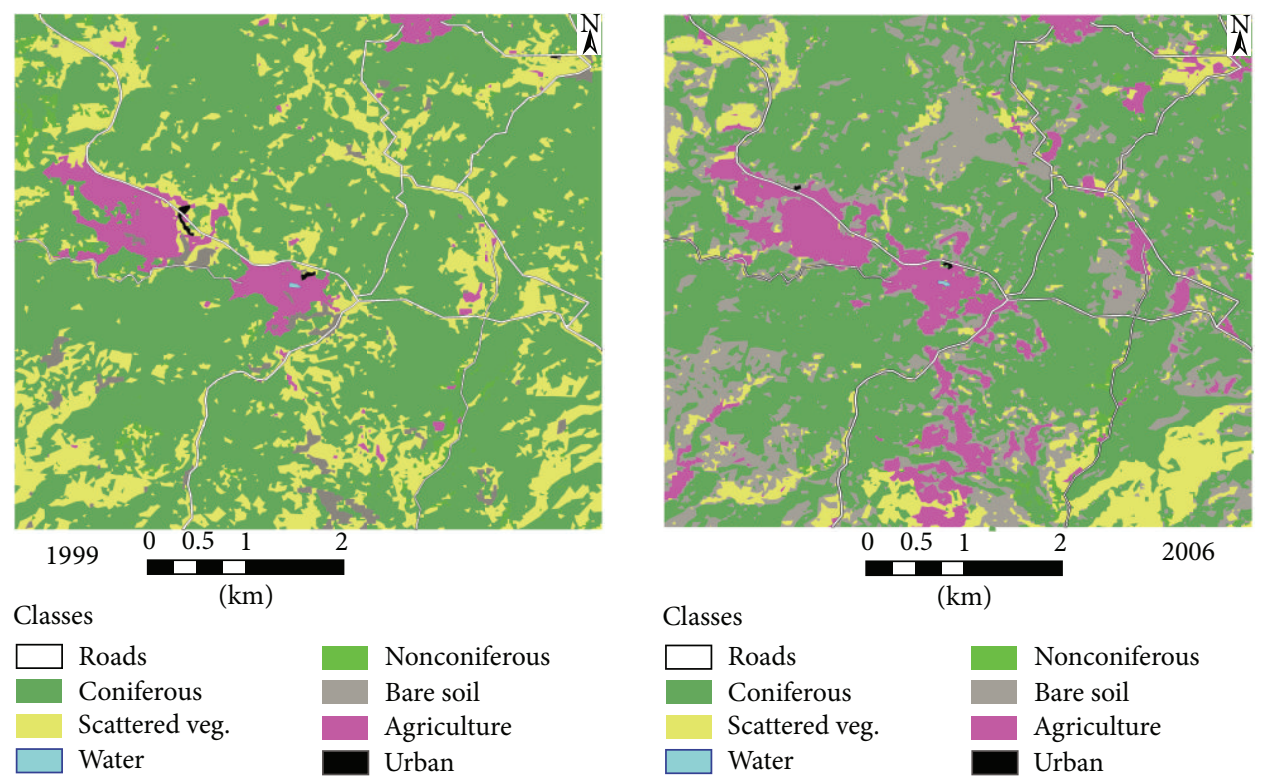

FIGURE 2: Maps of the classified study area for 1999 and 2006 where the observed increase in bare soil and agriculture classes and decrease in forested land are presented.

were those alleged to have an impact on the woody plant species, richness and diversity (see [39-41]). As the different patches were surrounded by a different LULC (Land Use/Land Cover) matrix, different contrast values were given to each contrast combination depending on the cover classes
(Table S1 See Supplementary Material available online at http://dx.doi.org/10.1155/2014/384698). For a full description of the variables see McGarigal et al. [31].

The fragmentation indices were obtained with the Patch Analyst extension v.4 [42] for ArcInfo, using the classified 
TABLE 2: Patch variables used for the analysis (fragmentation variables from [31]). ENN, ECON, and CONTIG were calculated in Fragstats v.3.3, raster environment with the 8-pixel rule.

\begin{tabular}{|c|c|c|}
\hline Variable & Explanation & Range \\
\hline Area $\left(\mathrm{km}^{2}\right)$ & Equals the patch's area & $0.0009-10.13$ \\
\hline CONTIG & Patch's contiguity & $0-0.92$ \\
\hline Core area $\left(\mathrm{km}^{2}\right)$ & Equals the core area & $0.0000-9.40$ \\
\hline Core FD & $\begin{array}{c}\text { Core area fractal } \\
\text { dimension }\end{array}$ & $0-1.86$ \\
\hline Core PAR & $\begin{array}{c}\text { Cores' area } \\
\text { perimeter-area ratio }\end{array}$ & $0-0.78$ \\
\hline Core perimeter $(\mathrm{m})$ & Core area perimeter & $0-73363$ \\
\hline Core SI & $\begin{array}{l}\text { Shape index of the } \\
\text { core area }\end{array}$ & $0-6.74$ \\
\hline $\mathrm{ECON}^{*}(\%)$ & Patch's edge contrast & $0-1$ \\
\hline Elevation (masl.) & Patch's elevation & $2500-2800$ \\
\hline $\operatorname{ENN}\left(\mathrm{m}^{2}\right)$ & $\begin{array}{l}\text { Patch's Euclidean } \\
\text { nearest neighbour }\end{array}$ & $60-942$ \\
\hline FD & $\begin{array}{l}\text { Patch's fractal } \\
\text { dimension }\end{array}$ & $1.31-1.55$ \\
\hline Latitude (m) & Geographic location & $3084590-3094000$ \\
\hline Longitude (m) & Geographic location & $262754-272468$ \\
\hline PAR & Perimeter-area ratio & $0.007-0.20$ \\
\hline Perimeter (m) & Patch's perimeter $(\mathrm{m})$ & $120-71276$ \\
\hline PROX & $\begin{array}{l}\text { Patch's proximity } \\
\text { index }\end{array}$ & $0.001-6610.48$ \\
\hline SI & $\begin{array}{l}\text { Shape index of the } \\
\text { patch }\end{array}$ & $1.12-6.31$ \\
\hline Slope (degrees) & Patch's slope & $0^{\circ}-30^{\circ}$ \\
\hline
\end{tabular}

${ }^{*}$ Edge contrast values between LULC classes are presented in the Supplementary Material.

layer of 2006 in polygon format as input data. All the calculations were carried out in a polygon environment with the exception of the Euclidean nearest neighbour, edge contrast and contiguity, which was obtained using the raster environment in the software Fragstats v.3.3 [31]. In addition to the fragmentation variables, elevation, latitude, longitude, and slope data were used as explanatory variables. All the explanatory variables were $l n$-transformed in order to improve the normality of the data.

3.6. Data Analysis. Preliminary analysis of the explanatory variables showed that four of the sampled polygons had extreme values for the shape index variable $(\mathrm{SI}>2.62)$ in comparison to the other polygons' values. Consequently these fragments were not used for further analyses as they could mask the real pattern of the data [43].

A principal component analysis (PCA) was carried out in order to concentrate the information of the fragmentation variables into a small number of components. The association between all pairs of explanatory variables was evaluated by means of Spearman correlation coefficients. The differences between forests types with respect to the patch variables analysed were assessed with the Kruskal-Wallis test. These
TABLE 3: Loadings for the four components extracted from the PCA analysis and the $\%$ of variation explained by each one.

\begin{tabular}{lcccc}
\hline Axes extracted & $\begin{array}{c}\text { PCA 1 } \\
(50.96 \%)\end{array}$ & $\begin{array}{c}\text { PCA 2 } \\
(16.74 \%)\end{array}$ & $\begin{array}{c}\text { PCA 3 } \\
(11.65 \%)\end{array}$ & $\begin{array}{c}\text { PCA 4 } \\
(7.66 \%)\end{array}$ \\
\hline Variable & & & & \\
Area $\left(\mathrm{m}^{2}\right)$ & 0.98 & 0.09 & -0.03 & 0.06 \\
CONTIG & 0.34 & -0.22 & 0.29 & 0.68 \\
Core area $\left(\mathrm{m}^{2}\right)$ & 0.97 & -0.03 & -0.09 & -0.15 \\
Core FD & -0.49 & 0.48 & 0.11 & -0.48 \\
Core PAR & -0.94 & 0.28 & 0.13 & 0.04 \\
Core perimeter & 0.94 & 0.12 & -0.06 & -0.22 \\
Core SI & 0.60 & 0.74 & 0.09 & -0.06 \\
ECON & -0.02 & -0.24 & 0.59 & -0.10 \\
ENN & -0.45 & 0.17 & -0.57 & 0.42 \\
FD & -0.57 & 0.71 & 0.30 & 0.20 \\
PAR & -0.96 & 0.21 & 0.14 & 0.01 \\
Perimeter $(\mathrm{m})$ & 0.94 & 0.28 & 0.04 & 0.11 \\
PROX & 0.13 & -0.34 & 0.80 & 0.01 \\
SI & 0.56 & 0.74 & 0.23 & 0.21 \\
\hline
\end{tabular}

analyses were carried out using " $\mathrm{R}$ " statistical software v.2.11.1 [44]. The Kruskal-Wallis test was used to investigate if there was a significant difference in the species' dispersal mechanisms per forest class.

Subsequently, multiple regression analyses with a backward selection procedure were used to determine how the Shannon diversity index $\left(H^{\prime}\right)$, and plant species' richness ( $S$, plant species per plot) of woody plants depended on the forest fragmentation status as concentrated into the PCA factors, elevation, latitude, longitude, and slope data (see also Table S2). The regression analyses were done on the basis of all 96 patches (complete dataset) and, separately, on the basis of the fragments belonging to each forest type, in order to analyse how the patches' fragmentation characteristics might impact different forest vegetation types. The statistical analyses were carried out using "R" statistical software v.2.11.1 [44] with the use of the package "vegan" [45].

\section{Results}

4.1. Forest Fragmentation. The PCA analysis resulted in the extraction of four components considered for further analysis. Following the Kaiser-Guttman criterion [46, 47], PCA axes with eigenvalues above 1 were retained. The extracted components explained $87 \%$ of the total variance in the data (Table 3 ). The main variables loading the four extracted PCA fragmentation factors were a combination between the area and perimeter data for the first axis, which had the highest eigenvalue (7.13); shape for the second axis; proximity for the third axis; and contiguity for the fourth axis extracted. The combination of these factors had the highest significance as they explained most of the variance in the fragmentation data for the three forest classes (Figures 3(a) and 3(b)). The exploratory correlation analysis between the fragments' 
TABLE 4: The Spearman rank correlations were carried out between the four PCA factors extracted, slope, elevation, longitude, and latitude variables.

\begin{tabular}{|c|c|c|c|c|c|c|c|c|}
\hline Fragment variable & Slope & Elevation & Longitude & Latitude & PCA 1 & PCA 2 & PCA 3 & PCA 4 \\
\hline \multicolumn{9}{|l|}{ Slope } \\
\hline Correlation coeff. & 1 & -0.24 & 0.15 & -0.47 & -0.03 & -0.04 & 0.02 & -0.10 \\
\hline$P$ value & . & 0.02 & 0.14 & 0.00 & 0.74 & 0.71 & 0.84 & 0.31 \\
\hline \multicolumn{9}{|l|}{ Elevation } \\
\hline Correlation coeff. & & 1 & 0.01 & 0.52 & -0.21 & 0.07 & -0.06 & -0.07 \\
\hline$P$ value & & . & 0.89 & 0.00 & 0.04 & 0.50 & 0.57 & 0.52 \\
\hline \multicolumn{9}{|l|}{ Longitude } \\
\hline Correlation coeff. & & & 1 & 0.10 & -0.11 & -0.05 & -0.35 & 0.06 \\
\hline$P$ value & & & . & 0.32 & 0.29 & 0.60 & 0.00 & 0.56 \\
\hline \multicolumn{9}{|l|}{ Latitude } \\
\hline Correlation coeff. & & & & 1 & -0.02 & 0.01 & -0.05 & -0.07 \\
\hline$P$ value & & & & . & 0.88 & 0.91 & 0.64 & 0.48 \\
\hline \multicolumn{9}{|l|}{ PCA factor 1 (area) } \\
\hline Correlation coeff. & & & & & 1 & 0.07 & 0.05 & 0.32 \\
\hline$P$ value & & & & & . & 0.47 & 0.62 & 0.00 \\
\hline \multicolumn{9}{|l|}{ PCA factor 2 (shape) } \\
\hline Correlation coeff. & & & & & & 1 & -0.03 & 0.05 \\
\hline$P$ value & & & & & & . & 0.74 & 0.63 \\
\hline \multicolumn{9}{|c|}{ PCA factor 3 (proximity) } \\
\hline Correlation coeff. & & & & & & & 1 & -0.05 \\
\hline$P$ value & & & & & & & . & 0.60 \\
\hline \multicolumn{9}{|c|}{ PCA factor 4 (contiguity) } \\
\hline Correlation coeff. & & & & & & & & 1 \\
\hline$P$ value & & & & & & & & . \\
\hline
\end{tabular}

Significant values are highlighted.

TABLE 5: Difference in mean values of the patch's variables used as input data for the linear regression analysis. The data is analysed between forest types. Information on geographic location of the patches is not included in the table. PCA 1: area; PCA 2: shape; PCA 3: proximity; PCA 4: contiguity.

\begin{tabular}{|c|c|c|c|c|c|c|}
\hline Forest class & $\begin{array}{c}\text { PCA } 1 \text { mean } \pm \\
1 \mathrm{SD}\end{array}$ & $\begin{array}{c}\text { PCA } 2 \text { mean } \pm \\
1 \text { SD }\end{array}$ & $\begin{array}{c}\text { PCA } 3 \text { mean } \pm \\
1 \text { SD }\end{array}$ & $\begin{array}{c}\text { PCA } 4 \text { mean } \pm \\
1 \text { SD }\end{array}$ & $\begin{array}{c}\text { Slope mean } \pm \\
1 \mathrm{SD}\end{array}$ & $\begin{array}{c}\text { Elevation } \\
\text { mean } \pm 1 \text { SD }\end{array}$ \\
\hline Coniferous & $-0.08 \pm 1.08$ & $-0.46 \pm 0.84$ & $0.88 \pm 0.95$ & $0.20 \pm 1.49$ & $8.69 \pm 6.46$ & $2563.82 \pm 48.97$ \\
\hline Nonconiferous & $0.10 \pm 0.99$ & $0.37 \pm 0.91$ & $-0.54 \pm 0.72$ & $0.008 \pm 0.62$ & $12 \pm 9.93$ & $2567.27 \pm 75.39$ \\
\hline Scattered veg. & $0.03 \pm 0.94$ & $0.03 \pm 1.06$ & $0.22 \pm 0.74$ & $0.18 \pm 0.71$ & $7.46 \pm 6.96$ & $2552.85 \pm 48.94$ \\
\hline Kruskal-Wallis H & 0.501 & 11.07 & 35.08 & 0.58 & 4.54 & 1.95 \\
\hline$P$ value & 0.77 & 0.00 & $2.4 e^{-8}$ & 0.74 & 0.10 & 0.37 \\
\hline
\end{tabular}

variables showed weak or no significant correlations; consequently, all of them were included in further analyses (Table 4). The three forest types only differed significantly in the fragmentation values for the variables Shape index and Proximity between patches (Table 5).

4.2. Plant Species, Richness and Diversity. In total, we recoded 2491 woody plants. Data from 139 individuals was discarded as they belonged to the 4 eliminated plots. The final analyses were carried out on the basis of data from 2352 plant individuals belonging to 17 species within 7 plant families, which presented two main seed dispersal mechanismsanemochory and zoochory (Table S3) A significant difference in species richness and diversity among forest classes, where the coniferous forest showed the highest values, followed by the non-coniferous forest and the scattered vegetation class, was found (Table 6).

4.3. Forest Fragments Characteristics and Species, Richness and Diversity. The results of the multiple regression models (96 plots) showed that only the "Proximity" between forest fragments had a significant effect on the woody plant species, richness but none on the species diversity (Table $7(\mathrm{a})$ ). It is also shown that the slope and elevation characteristics of the fragments greatly influence the woody plants species, richness and diversity of the study area. The multiple regression 


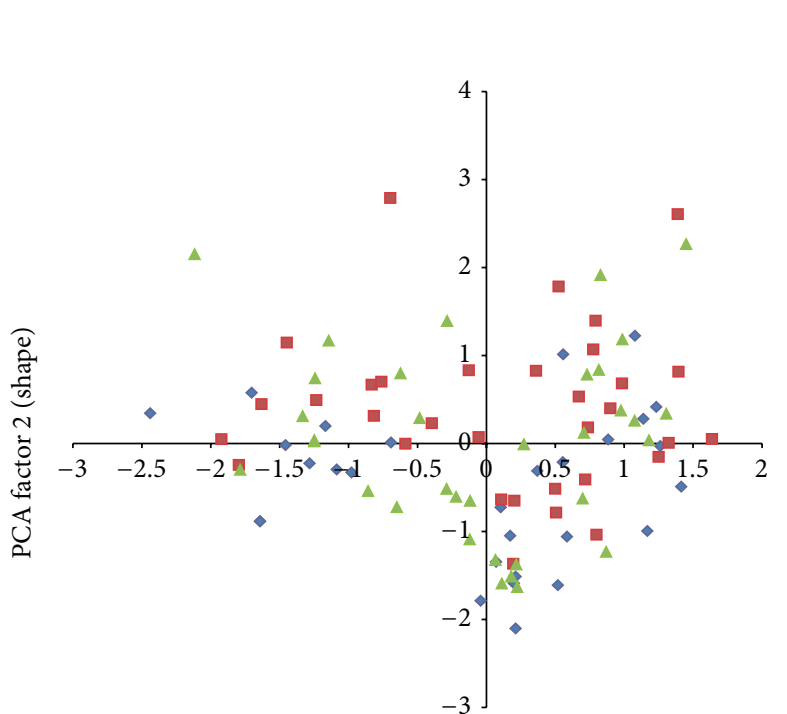

PCA factor 1 (area-perimeter)

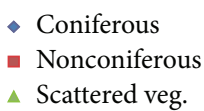

A Scattered veg.

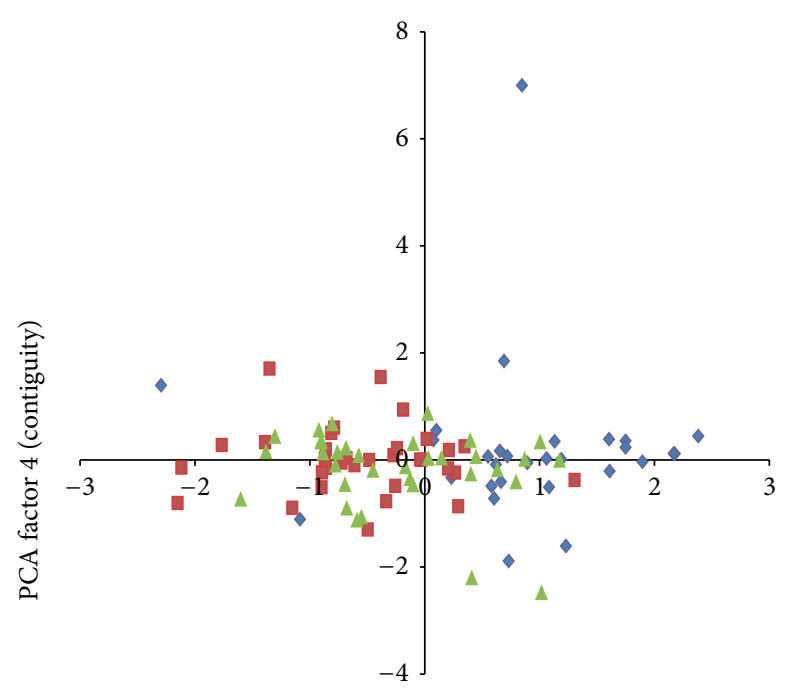

PCA factor 3 (proximity)

- Coniferous

- Nonconiferous

$\triangle$ Scattered veg.

(a)

(b)

FIGURE 3: (a) The 1st and 2nd PCA factors extracted; these are mainly composed of variables related to area-perimeter and shape index. (b) The 3rd and 4th PCA factors loaded by variables related to the patch's proximity and contiguity.

TABLE 6: Comparison of the mean values of woody plant species' richness and species' diversity between forest classes.

\begin{tabular}{lcc}
\hline Forest class & Species $S$ mean $\pm 1 \mathrm{SD}$ & Species $H^{\prime}$ mean $\pm 1 \mathrm{SD}$ \\
\hline Coniferous & $5.34 \pm 2$ & $1.27 \pm 0.45$ \\
Nonconiferous & $5 \pm 1.98$ & $1.23 \pm 0.40$ \\
Scattered veg. & $3.73 \pm 1.65$ & $0.96 \pm 0.47$ \\
Kruskal-Wallis $\mathrm{H}$ & 10.34 & 13.25 \\
$P$ value & 0.005 & 0.001 \\
\hline
\end{tabular}

models did not detect any significant relation between fragmentation variables and the woody plants $S$ and $H^{\prime}$ when the data was analysed by forest type. However, the slope and spatial location variables showed a significant interaction with the species' richness and diversity and differed according to forest class (Table 7(b)).

The coniferous forest species' richness was negatively related to the longitudinal location but did not present any relation with the fragmentation factors analysed. Furthermore, none of the variables included in the regression analysis interacted with species, diversity of this forest type. For the non-coniferous forest a positive correlation between diversity and the slope of the forest fragments was obtained. In this forest class the steeper sites showed higher species, diversity. Species, richness was not significantly related to any of the fragments variables studied.

The regression models for the scattered vegetation showed no effect of fragment characteristics on the woody plants species, richness and diversity (Table $7(\mathrm{~b})$ ). In this forest, species, richness was negatively related to the latitudinal location of the fragments. In fragments located in the north of the study area lower species, diversity values were observed. This forest class showed a positive interaction with the fragments slope values, as the steeper locations were richer in woody plants.

\section{Discussion}

5.1. Fragments Properties and Plant Species, Richness and Diversity. Fragmentation effects on the plant community strongly differed according to forest class (Table 7(a)-(b)). Overall, the plant species' richness was positively related to "proximity" between fragments, as less isolated patches showed greater species" richness. However, the "slope" of the fragments was the most important variable determining the woody plants species' richness and diversity.

The results showed that greater proximity between patches (reducing isolation) within forest class increases species' richness and diversity. Similar results have been found in the highlands of Chiapas, Mexico, by Ochoa-Gaona et al. [15] and in the south of Chile by Echeverría et al. [48], where proximity between forest fragments is considered an important factor for the plant populations' survival, as the opportunity and capability of the species to colonize other fragments highly depend on the distance between the focal patch and other patches of the same type [49].

In this study it was observed that the area-perimeter of the patches did not have an effect on the species, richness and 
TABLE 7: Results of the multiple regression analyses using (a) the complete plots dataset (96 plots) and (b) the dataset divided by forest type.

\begin{tabular}{|c|c|c|c|c|c|c|c|}
\hline Analysis & $\begin{array}{c}\text { Response } \\
\text { variable }\end{array}$ & $R_{\text {Adj. }}^{2}$ & $F$ & ${ }^{*} P$ model & $\begin{array}{c}\text { Explanat. } \\
\text { variable }\end{array}$ & $\begin{array}{c}\text { Standardized } \\
\text { coefficient }\end{array}$ & ${ }^{*} P$ coefficient \\
\hline \multirow{4}{*}{ (a) Complete dataset } & $H^{\prime}$ & 0.16 & 5.64 & 0.00 & Slope & 0.34 & 0.00 \\
\hline & & & & & Elevation & 0.25 & 0.02 \\
\hline & $S$ & 0.13 & 8.38 & 0.00 & Slope & 0.32 & 0.00 \\
\hline & & & & & Proximity & 0.20 & 0.03 \\
\hline \multicolumn{8}{|l|}{ (b) Forest types } \\
\hline \multirow{2}{*}{ Coniferous } & $H^{\prime}$ & - & - & - & - & - & - \\
\hline & $S$ & 0.13 & 5.17 & 0.030 & Longitude & -0.40 & 0.03 \\
\hline \multirow{2}{*}{ Nonconiferous } & $H^{\prime}$ & 0.17 & 7.84 & 0.00 & Slope & 0.44 & 0.00 \\
\hline & $S$ & - & - & - & - & - & - \\
\hline \multirow{2}{*}{ Scattered veg. } & $H^{\prime}$ & 0.19 & 3.66 & 0.02 & Latitude & -0.38 & 0.02 \\
\hline & $S$ & 0.20 & 5.30 & 0.01 & Slope & 0.35 & 0.03 \\
\hline
\end{tabular}

${ }^{*} P$ : significance of the model and coefficient.

-: not significant.

diversity. This finding concurs with those of Ochoa-Gaona et al. [15], who did not find any relation between fragment size and tree species' richness in the south of Mexico. If fragments characteristics are studied separately for each forest type, it is shown that the species' richness of the coniferous class is negatively related to the longitudinal location of the forest patches. Notoriously, the steeper locations are found in the south east of the study area where less coniferous forest is observed (Figure 2). The non-coniferous forest did not present any significant effect of fragmentation on species richness and diversity. However, it does not mean that there are no other fragmentation variables that could be impacting this forest class and, in general, the three forest classes analysed.

Species' diversity showed a negative relation with the increment in latitude in the case of the scattered vegetation forest class. The scattered vegetation forest class is the one with the lowest values for the species' richness and diversity, which might be explained by three reasons: (1) the scattered vegetation class comprises mostly shrub species spread out in the patch area, (2) this forest class has more bare soil area available than the coniferous and non-coniferous forest classes, and (3) as observed in the field data collection, these scattered vegetation areas emerge more often after the logging processes, which mostly select Pinus and Quercus tree species [50]. Thus, the processes involved seem to be mostly related to species colonization rather than to fragmentation effects. Moreover, these activities mainly occur in northern latitudes where the area is flatter and the access to roads increases. The proximity between forest fragments showed a high interaction with the slope and elevation, and in most of the cases these two variables had a stronger relation with the woody plants species' richness and diversity than the fragmentation variables per se.

\section{Conclusions}

It is shown in this study that fragmentation effects on the woody plant species are not strong and that these depend on the forest type studied. Furthermore, it is shown that environmental factors, as slope characteristics, play a major role in determining species, richness and diversity at the plot scale ( $100 \mathrm{~m}^{2}$ sampling plot). In our study it is apparent that different forest classes respond in a different way and have different resilience to habitat fragmentation effects. It is further shown the contrasting effects of environmental characteristics and fragmentation depend on the vegetation studied and render more insight into the discussion on the effects of habitat fragmentation on plants, richness and diversity. The results of this study suggest that fragmentation must be analyzed in a broader scale, for the fragment as a whole, as the community assembly at a small sample scale area $\left(100 \mathrm{~m}^{2}\right)$ seems to be more influenced by ecological filters related to environmental variables limiting plant establishment and biotic filters related to competition than to factors limiting species colonization (e.g., isolation). Essentially, conservation actions should be guided by the particular vegetation class analysed and by the specific fragmentation/environmental variable(s) impacting the forest type under study, as the different vegetation types responses to the fragmentation effects have been widely shown. It is essential to investigate the forest fragmentation effects on biodiversity at the landscape level, followed by an in-depth analysis at the forest type level (finer scale) in order to obtain more detailed information about the effect of fragmentation in the species' richness and diversity on different vegetation classes.

In this particular area, conservation efforts should be directed to reduce isolation between forest fragments, as this has a significant impact on the species' richness and diversity. This highlights the importance that seed dispersal plays for the plant communities' in this particular study area, as colonization and genetic exchange might be facilitated in forest fragments that are contiguous or closer to each other. There was no evidence showing an impact of fragment size on the woody plant species' $S$ and $H^{\prime}$ in this particular forest area. However, as observed in our results, the proximity between patches is highly important for maintaining the $S$ and $H^{\prime}$. Because of this management, action for this area 
must focus on primary conservation of the already proximal patches, avoid their further division, and increase their connectivity. This might then contribute to the regeneration of the forest by means of the species dispersal between closely located fragments.

\section{Conflict of Interests}

The author declares that there is no conflict of interests regarding the publication of this paper.

\section{Acknowledgments}

This research was funded by the Netherlands Universities Foundation for International Cooperation (Nuffic), a grant from the "Amsterdamse Universiteits Vereniging (AUV)", and a "STUNT" grant from the University of Amsterdam. Misión Indígena Bawinokachi and Maria Pontes are thanked for their logistical support. Luz Maria Stanek and Jorge Alberto Pérez de la Rosa (University of Guadalajara at CUCBA) are thanked for their help with the species identification.

\section{References}

[1] G. Çakir, F. Sivrikaya, and S. Keleş, "Forest cover change and fragmentation using Landsat data in Maçka State Forest Enterprise in Turkey," Environmental Monitoring and Assessment, vol. 137, no. 1, pp. 51-66, 2008.

[2] L. D. Harris, The Fragmented Forest: Island Biogeography Theory and the Preservation of Biotic Diversity, University of Chicago Press, 1984.

[3] S. Kilic, F. Evrendilek, S. Berberoglu, and A. C. Demirkesen, "Environmental monitoring of land-use and land-cover changes in a Mediterranean Region of Turkey," Environmental Monitoring and Assessment, vol. 114, no. 1-3, pp. 157-168, 2006.

[4] W. F. Laurance, "Reflections on the tropical deforestation crisis," Biological Conservation, vol. 91, no. 2-3, pp. 109-117, 1999.

[5] K. S. Rao and R. Pant, "Land use dynamics and landscape change pattern in a typical micro watershed in the mid elevation zone of central Himalaya, India," Agriculture, Ecosystems and Environment, vol. 86, no. 2, pp. 113-124, 2001.

[6] W. D. Robinson and T. W. Sherry, "Mechanisms of avian population decline and species loss in tropical forest fragments," Journal of Ornithology, vol. 153, no. 1, pp. 141-152, 2012.

[7] A. Farina, Principles and Methods in Landscape Ecology, Springer, New York, NY, USA, 2006.

[8] M. G. Turner, R. H. Gardner, and R. V. O'Neill, Landscape Ecology in Theory and Practice: Pattern and Process, Springer, New York, NY, USA, 2001.

[9] Y. Haila, "A conceptual genealogy of fragmentation research: from island biogeography to landscape ecology," Ecological Applications, vol. 12, no. 2, pp. 321-334, 2002.

[10] D. Urban and T. Keitt, "Landscape connectivity: a graphtheoretic perspective," Ecology, vol. 82, no. 5, pp. 1205-1218, 2001.

[11] K. Ethier and L. Fahrig, "Positive effects of forest fragmentation, independent of forest amount, on bat abundance in eastern Ontario, Canada," Landscape Ecology, vol. 26, no. 6, pp. 865876, 2011.
[12] A. C. Smith, L. Fahrig, and C. M. Francis, "Landscape size affects the relative importance of habitat amount, habitat fragmentation, and matrix quality on forest birds," Ecography, vol. 34, no. 1, pp. 103-113, 2011.

[13] M. Schleuning, N. Farwig, M. K. Peters et al., "Forest fragmentation and selective logging have inconsistent effects on multiple animal-mediated ecosystem processes in a tropical forest," PLoS ONE, vol. 6, no. 11, Article ID e27785, 2011.

[14] H. Jacquemyn, R. Brys, and M. Hermy, "Patch occupancy, population size and reproductive success of a forest herb (Primula elatior) in a fragmented landscape," Oecologia, vol. 130, no. 4, pp. 617-625, 2002.

[15] S. Ochoa-Gaona, M. González-Espinosa, J. A. Meave, and V. S. Bon, "Effect of forest fragmentation on the woody flora of the highlands of Chiapas, Mexico," Biodiversity and Conservation, vol. 13, no. 5, pp. 867-884, 2004.

[16] S. Petit, L. Griffiths, S. S. Smart, G. M. Smith, R. C. Stuart, and S. M. Wright, "Effects of area and isolation of woodland patches on herbaceous plant species richness across Great Britain," Landscape Ecology, vol. 19, no. 5, pp. 463-472, 2004.

[17] J. S. Markl, M. Schleuning, P. M. Forget et al., "Meta-analysis of the effects of human disturbance on seed dispersal by animals," Conservation Biology, vol. 26, no. 6, pp. 1072-1081, 2012.

[18] J. K. Hill, M. A. Gray, C. V. Khen, S. Benedick, N. Tawatao, and K. C. Hamer, "Ecological impacts of tropical forest fragmentation: how consistent are patterns in species richness and nestedness?" Philosophical Transactions of the Royal Society B, vol. 366, no. 1582, pp. 3265-3276, 2011.

[19] S. P. Hubbell, The Unified Neutral Theory of Biodiversity and Biogeography, Princeton University Press, Princeton, NJ, USA, 2001.

[20] I. M. Turner and R. T. Corlett, "The conservation value of small, isolated fragments of lowland tropical rain forest," Trends in Ecology and Evolution, vol. 11, no. 8, pp. 330-333, 1996.

[21] A. Aparicio, R. G. Albaladejo, M. Á. Olalla-Tárraga, L. F. Carrillo, and M. Á. Rodríguez, "Dispersal potentials determine responses of woody plant species richness to environmental factors in fragmented Mediterranean landscapes," Forest Ecology and Management, vol. 255, no. 7, pp. 2894-2906, 2008.

[22] M. J. Struebig, T. Kingston, E. J. Petit et al., "Parallel declines in species and genetic diversity in tropical forest fragments," Ecology Letters, vol. 14, no. 6, pp. 582-590, 2011.

[23] J. C. Biesmeijer, S. P. M. Roberts, M. Reemer et al., "Parallel declines in pollinators and insect-pollinated plants in Britain and the Netherlands," Science, vol. 313, no. 5785, pp. 351-354, 2006.

[24] M. Gonzalez, M. Deconchat, and G. Balent, "Woody plant composition of forest layers: the importance of environmental conditions and spatial configuration," Plant Ecology, vol. 201, no. 1, pp. 305-318, 2009.

[25] E. Weiher and A. Howe, "Scale-dependence of environmental effects on species richness in oak savannas," Journal of Vegetation Science, vol. 14, no. 6, pp. 917-920, 2003.

[26] CIF, Conservation International Foundation, 2009.

[27] L. Arriaga, J. M. Espinoza, C. Aguilar, E. Martínez, L. Gómez, and E. Loa, Regiones terrestres prioritarias de México, Comisión Nacional para el Conocimiento y uso de la Biodiversidad, Mexico City, Mexico, 2000, http://www.conabio.gob.mx/ conocimiento/regionalizacion/doctos/Tlistado.html.

[28] INEGI (Instituto Nacional de Estadística Geografía e Informática), Fuente del sitio en internet, 2010, http://www .inegi.org. $\mathrm{mx} /$. 
[29] ESRI, ESRI, Redlands, Calif, USA, 2012

[30] J. Aguirre-Gutiérrez, A. C. Seijmonsbergen, and J. F. Duivenvoorden, "Optimizing land cover classification accuracy for change detection, a combined pixel-based and object-based approach in a mountainous area in Mexico," Applied Geography, vol. 34, pp. 29-37, 2012.

[31] K. McGarigal, S. A. Cushman, M. C. Neel, and E. Ene, FRAGSTATS: Spatial Pattern Analysis Program for Categorical Maps, Computer software program the University of Massachusetts, Amherst, Mass, USA, 2002, http://www.umass.edu/ landeco/research/fragstats/fragstats.html.

[32] H. L. Beyer, Hawth's Analysis Tools for ArcGIS, 2004, http://www .spatialecology.com/htools.

[33] E. Wakild, "Environment and environmentalism," in A Companion to Mexican History and Culture, W. H. Beezley, Ed., pp. 518-537, Wiley-Blackwell, Oxford, UK, 2011.

[34] F. B. Zuñiga, Técnicas de muestreo para manejadores de recursos naturales, Instituto Nacional de Ecología, 2004.

[35] A. Farjon and B. T. Styles, Pinus (Pinaceae), vol. 75, Botanical Garden Press, New York, NY, USA, 1997.

[36] A. Farjon, J. A. P. de la Rosa, and B. T. Styles, Guía de campo de los Pinos de México y América Central, Royal Botanic Gardens, Kew, London, UK, 2000.

[37] D. M. Richardson, Ecology and Biogeography of Pinus, Cambridge University Press, Cambridge, UK, 1998.

[38] Garmin, Etrex, HC, Garmin International Inc., Olathe Kan, USA, 2010.

[39] I. T. Galanes and J. R. Thomlinson, "Relationships between spatial configuration of tropical forest patches and woody plant diversity in northeastern Puerto Rico," Plant Ecology, vol. 201, no. 1, pp. 101-113, 2009.

[40] A. Martínez-Morales, "Landscape patterns influencing bird assemblages in a fragmented neotropical cloud forest," Biological Conservation, vol. 121, no. 1, pp. 117-126, 2005.

[41] S. Ochoa-Gaona, "Traditional land-use systems and patterns of forest fragmentation in the highlands of Chiapas, Mexico," Environmental Management, vol. 27, no. 4, pp. 571-586, 2001.

[42] R. S. Rempel, D. Kaukinen, and A. P. Carr, Patch Analyst and Patch Grid, Ontario Ministry of Natural Resources, Centre for Northern Forest Ecosystem Research, Thunder Bay, Canada, 2012.

[43] A. F. Zuur, E. N. Ieno, N. J. Walker, A. A. Saveliev, and G. M. Smith, Mixed Effects Models and Extensions in Ecology with R, Springer, New York, NY, USA, 2009.

[44] R Development Core Team, $R$ : A Language and Environment for Statistical Computing, R Foundation for Statistical Computing, Vienna, Austria, 2013, http://www.r-project.org/.

[45] J. Oksanen, F. Guillaume, R. Kindt et al., "Vegan: community," Ecology Package, R package version 1.17-3, 2010, http://cran.rproject.org/package=vegan.

[46] P. Legendre and L. Legendre, Numerical Ecology, Elsevier, New York, NY, USA, 1998.

[47] D. A. Jackson, "Stopping rules in principal components analysis: a comparison of heuristical and statistical approaches," Ecology, vol. 74, no. 8, pp. 2204-2214, 1993.

[48] C. Echeverría, A. C. Newton, A. Lara, J. M. R. Benayas, and D. A. Coomes, "Impacts of forest fragmentation on species composition and forest structure in the temperate landscape of southern Chile," Global Ecology and Biogeography, vol. 16, no. 4, pp. 426-439, 2007.
[49] L. Cayuela, J. M. R. Benayas, and C. Echeverría, "Clearance and fragmentation of tropical montane forests in the Highlands of Chiapas, Mexico (1975-2000)," Forest Ecology and Management, vol. 226, no. 1-3, pp. 208-218, 2006.

[50] R. Gingrich, "Building effective international, multicultural alliances for restoration of ejido forests in the Sierra Madre Occidental," in Proceedings of the Connecting Mountain Islands and Desert Seas: Biodiversity and Management of the Madrean Archipelago II and 5th Conference on Research and Resource Management in the Southwestern Deserts, Tucson, Ariz, USA, May 2005. 

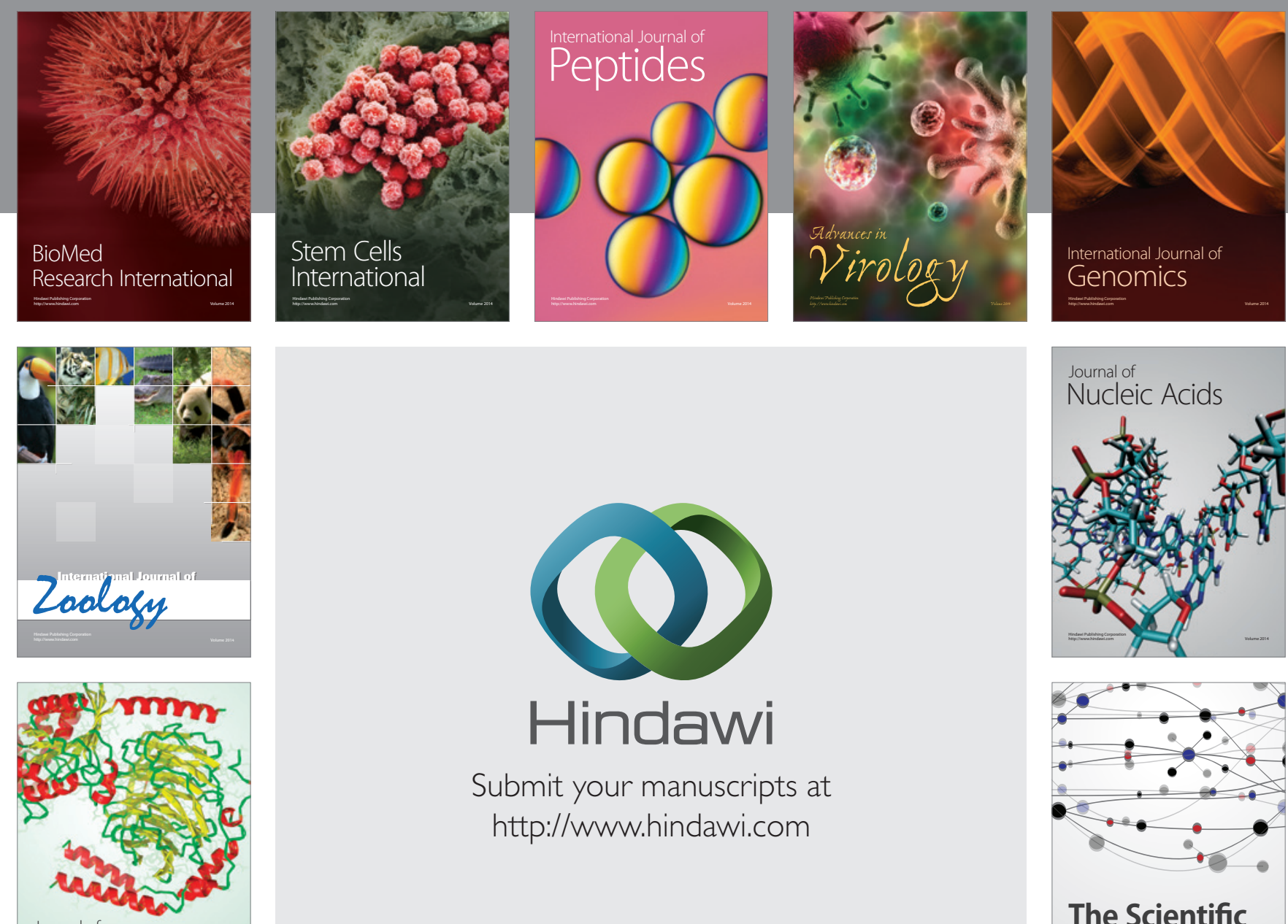

Submit your manuscripts at

http://www.hindawi.com

Journal of
Signal Transduction
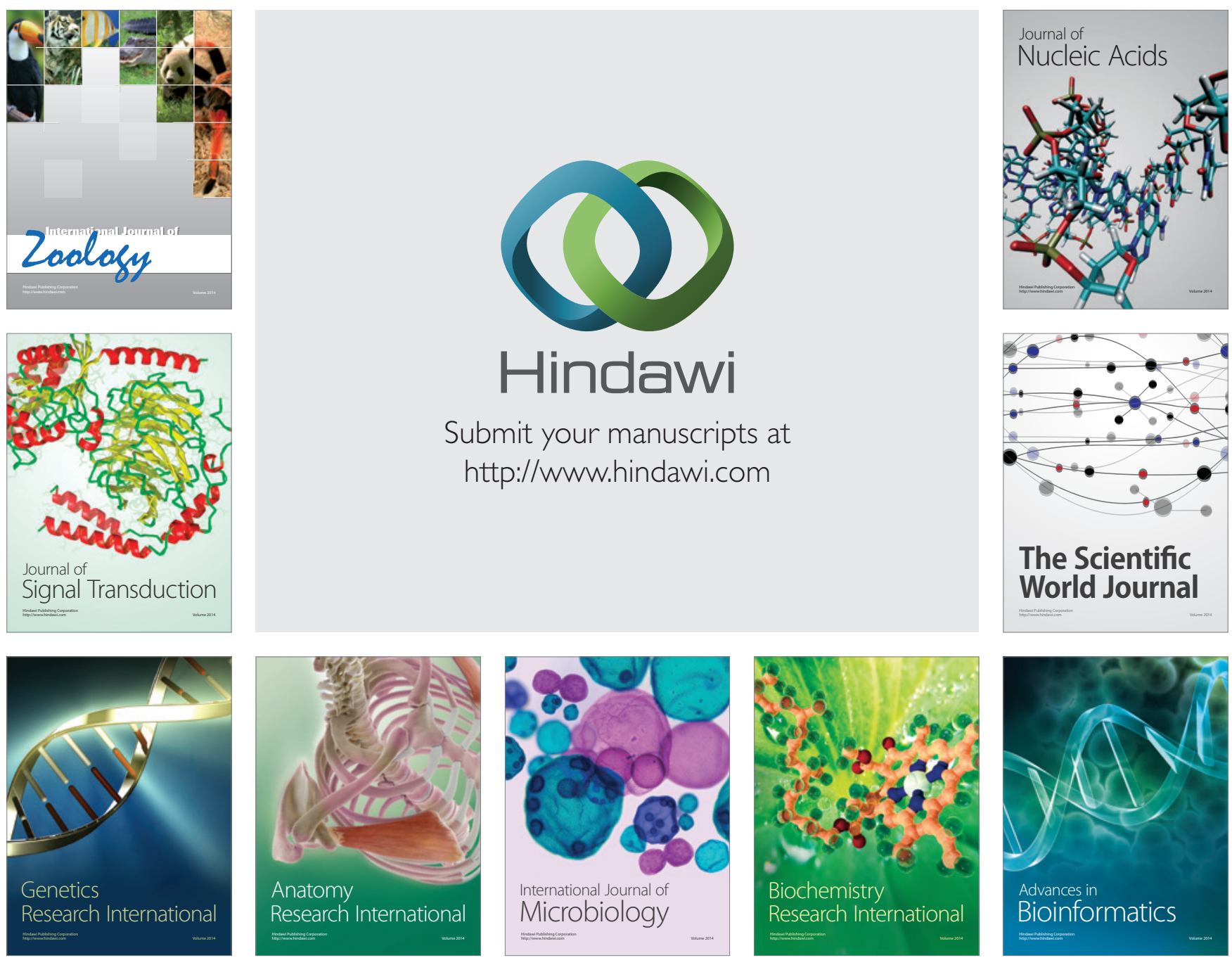

The Scientific World Journal
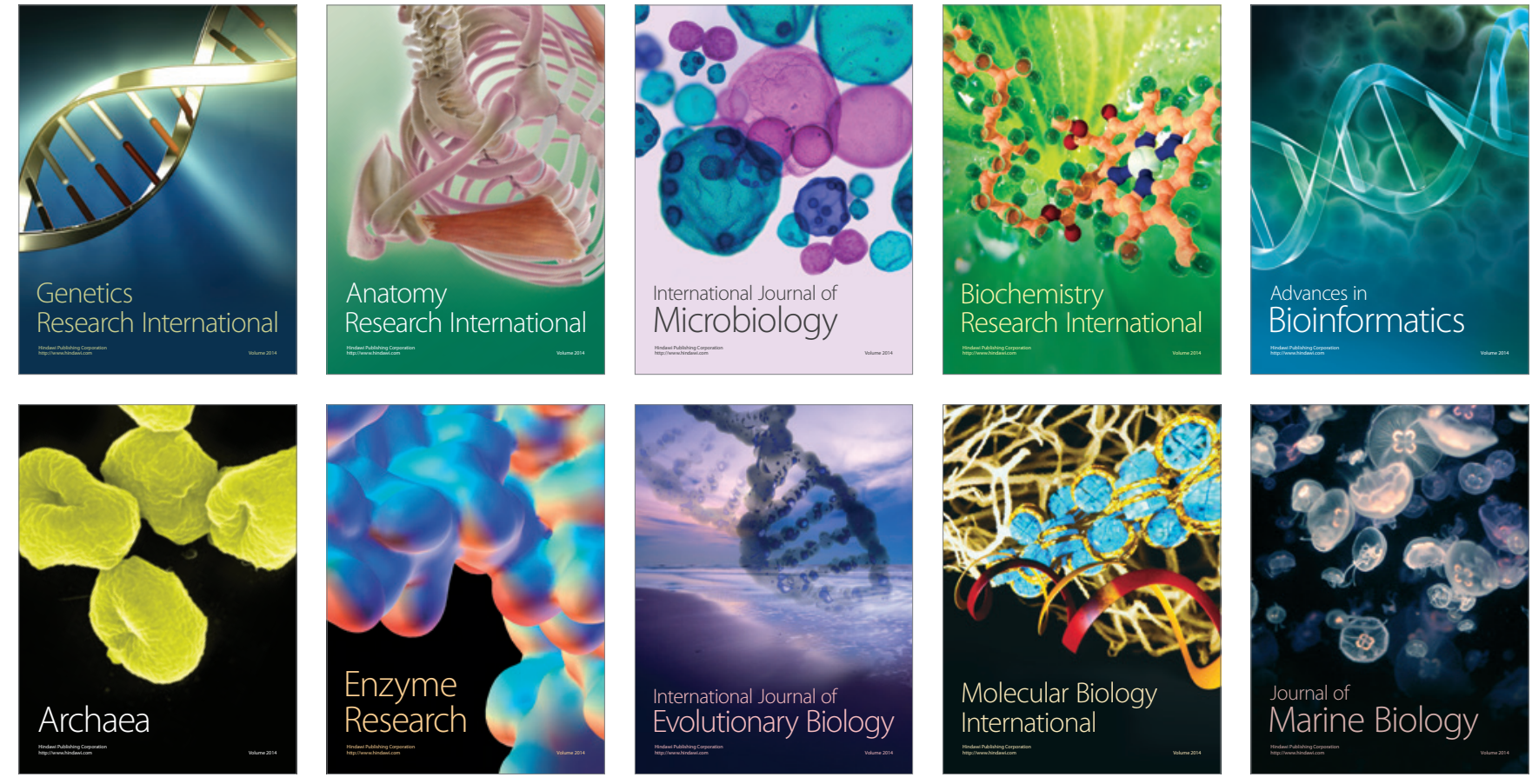